\title{
Characterization of Coil Faults in an Axial Flux Variable Reluctance PM Motor
}

\author{
Andrew L. Nelson and Mo-Yuen Chow, Senior Member, IEEE
}

\begin{abstract}
In recent years, variable-reluctance (VR) and switch-reluctance (SR) motors have been proposed for use in applications requiring a degree of fault tolerance. A range of topologies of brushless SR and VR permanent-magnet (PM) motors are not susceptible to some types of faults, such as phase-to-phase shorts, and can often continue to function in the presence of other faults. In particular, coil-winding faults in a single stator coil may have relatively little effect on motor performance but may affect overall motor reliability, availability, and longevity. It is important to distinguish between and characterize various winding faults for maintenance and diagnostic purposes. These fault characterization and analysis results are a necessary first step in the process of motor fault detection and diagnosis for this motor topology. This paper examines rotor velocity damping due to stator winding turn-to-turn short faults in a fault-tolerant axial flux VR PM motor. In this type of motor, turn-to-turn shorts, due to insulation failures, have similar $I-V$ characteristics as coil faults resulting from other problems, such as faulty maintenance or damage due to impact. In order to investigate the effects of these coil faults, a prototype axial flux VR PM motor was constructed. The motor was equipped with experimental fault simulation stator windings capable of simulating these and other types of stator winding faults. This paper will focus on two common types of winding faults and their effects on rotor velocity in this type of motor.
\end{abstract}

Index Terms-Axial flux motor, brushless dc motor, electric vehicle propulsion, failure analysis, fault tolerance, insulation failure, turn-to-turn fault, variable reluctance motor, winding fault.

\section{INTRODUCTION}

$\mathbf{F}$ OR SPECIALIZED applications, switch-reluctance (SR) and variable-reluctance (VR) permanent magnet (PM) motors are often designed to be less susceptible to various faults [1] and [2]. These motors generally possess a high degree of electrical and magnetic isolation between the stator phases. This makes phase to phase faults unlikely [1]. In addition, brushless versions of these motors with PM rotors lack rotor coils and commutator brushes and, hence, are not susceptible to faults involving these components. In many cases, it is found that SR and VR motors that have not been specifically designed for fault tolerance still possess a high degree of resistance to certain types of faults.

This paper focuses on the investigation and analysis of insulation failure that induced turn-to-turn stator coil shorts where a significant portion of the coil has been shorted out. This type of

Manuscript received February 26, 2001; revised December 20, 2001. This work was supported in part by the National Science Foundation Grants ECS9521609 and ECS-9610509.

The authors are with the Department of Electrical and Computer Engineering, North Carolina State University, Raleigh, NC 27695 USA.

Publisher Item Identifier 10.1109/TEC.2002.801730. fault can be the result of a single insulation failure between two adjacent coil turns if the turns happen to be in adjacent winding ranks. In the case of this particular fault, an associated drop in rotor velocity can be detected. In contrast, a similar fault, in which a portion of the coil is destroyed or removed in a manner that allows the remainder of the coil to continue to carry current, is not associated with a decrease in rotor velocity.

The prototype motor used in this work was designed to be similar to experimental in-wheel drives for electric vehicles and mobile machines. In addition, this motor was specifically designed to facilitate stator winding fault simulation. The motor has a relatively exposed architecture, enabling invasive testing and data collection. In particular, the coils in one of the stator phases have been wound to include a set of inter-turn taps. Each tap is connected through separate switches to a common ground. This arrangement allows several faults to be simulated experimentally. These simulated faults include coils with turn-to-turn shorts, coils with a reduced number of turns, and open-circuited phase faults.

\section{MOTOR DESCRIPTION}

The motor described in this work is an axial flux VR PM disc motor with 14 stator coils and four pairs of rotor PM poles. This motor was prototyped in the Advanced Diagnosis and Control (ADAC) laboratory at North Carolina State University. The prototype motor is shown in Fig. 1. In this motor design, the phrase "axial flux" indicates that the stator coils and rotor poles pairs are arranged so that the magnetic flux paths have components that are parallel to the axis of the rotor. This will be discussed in more detail with a description of the stator and rotor designs.

The motor is designed with seven stator phases. Each stator phase consists of two coils connected in series to form a total of 14 stator coils. The stator coils are wound on separate laminated cold-rolled steel cores, which are attached to a nonconducting substrate. The windings on each stator core are concentrated. Each stator coil is isolated from the others electrically and magnetically. The only iron in the stator is contained in the coil cores. The remainder of the stator is made up of nonconductive material and serves a structural roll only. These cores also serve as flux paths to direct the magnetomotive force (mmf) to the rotor. Each core has two machined surfaces that make up the stator side of the air gap.

The rotor is a disc with PMs embedded close to the edge of the disc so that each pole of every magnet is oriented toward one or the other face of the disc. The term "pole pair" refers to a set of north and south poles from a single PM. As with the stator coils, the rotor pole pairs are magnetically isolated from 


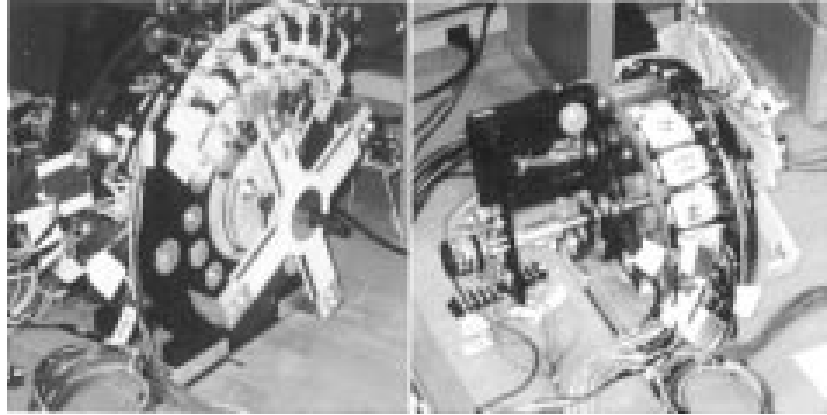

Fig. 1. Axial flux VR de motor.

one another. In this type of motor, flux does not pass through the center of the rotor, and the majority of the material that makes up the rotor is not conductive to magnetic flux. The rotor side of the air gap is made up of short iron flux paths that direct magnetic flux to/from the individual PM pieces.

A cross-sectional view of the motor topology depicting the relationship of the stator coils and the rotor poles is shown in Fig. 2. The arrangement of the four PM pieces in the rotor produces four axially oriented pole pairs spaced at 90-deg. intervals. Similarly, the stator coils are arranged to induce north and south poles oriented axially as to attract (or repel) a pair of rotor poles when energized.

A brushless dc motor driver strategy was used in this work. The motor driver implemented on the prototype motor uses an inner rotor position closed loop to commutate power switching to the stator phase. An outer open loop is used to control motor speed through a variable voltage source. Motors driven in this manner have similar dynamics comparable to those of traditional dc motors. This type of control is often used in electric vehicle propulsion systems where the vehicle operator controls the motor's speed and torque with an accelerator pedal.

\section{DESCRIPTION OF EXPERIMENTAL PlATFORM SETUP}

In this section, the experimental fault simulation platform used to generate and record the data presented in this paper is briefly described. The fault simulation platform is built around the prototype motor described earlier.

To facilitate the study of turn-to-turn coil faults, the coils in one of the stator phases (phase 1) were wound to include inter-turn taps. These taps were connected through separate switches to the phase common ground. The platform can be used to experimentally simulate turn-to-turn shorts involving between 1 and $50 \%$ of the coil turns. Such turn-to-turn faults result from insulation breakdown between the coil winding turns. Another related fault that can be simulated is one that results in a reduced number of coil turns but where the faulted portion of the coil is destroyed or removed. These faults can occur as a result of improper maintenance or damage due to impact.

The experimental fault simulation phase and a healthy phase were fitted with voltage and current sensors. In addition, a position encoder was mounted on the rotor shaft so that rotor position and velocity data could be recorded. Data were collected using National Instruments hardware and software.

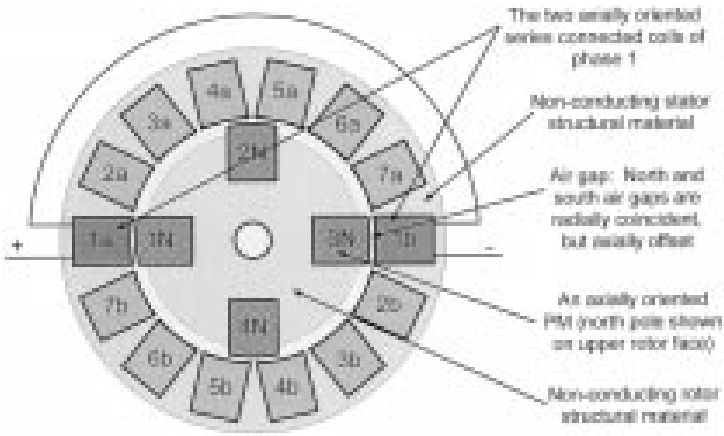

Fig. 2. Top cross-sectional view of the prototype motor showing the relative locations of the rotor pole pairs and the stator coils. Flux flows axially through a stator coil, then radially across the upper air gap, then axially through a single rotor PM, and then returns to the same coil across the low radial air gap. Only the north face of each rotor magnet is shown; the south poles would be seen if the motor were viewed from the reverse side.

\section{EXPERIMENTAL WINDING FAULT RESUlTS}

This section presents data and results generated with the prototype motor platform for unfaulted and faulted motor operation. In each experimental case, rotor position and velocity were recorded. In addition, voltage and current were measured on the experimental fault simulation phase and on a healthy phase. The experimental cases considered are described in the following paragraphs.

Fig. 3 will be referred to in the following descriptions of each of the fault cases. This figure illustrates the experimental fault simulation phase coil and tap switch configurations used in each case.

In the first case, the control no-fault case, the motor was run at steady state with only the $100 \%$ tap switch closed to ground. In this case, the fault test phase is expected to behave similarly to the other healthy phases. This case is illustrated in Fig. 3(a).

In the second case, data were collected with the $47 \%$ tap switch on the experimental fault simulation phase closed only (i.e., the $100 \%$ tap switch remains open). This case is illustrated in Fig. 3(b). This simulates a fault that may occur because of impact damage or improper maintenance so that the coil has a reduced number of turns. This case will be referred to as the reduced-coil fault. It should be noted that this is not the same as the turn-to-turn coil short, which is considered below.

Case 3 simulates a turn-to-turn fault where insulation has deteriorated, producing a low-resistance path from one winding rank to another. In this case, the $47 \%$ tap switch and the $100 \%$ tap switch are both closed. Here, the power source sees only $47 \%$ of the faulted phase coil, but the PM rotor-induced current can flow through the entire faulted phase. This case simulates a dramatic coil short where slightly more than half of the coil has been shorted out. This configuration is shown in part Fig. 3(c).

In addition, an open-circuited phase fault can be simulated by opening all of the tap switches including the $100 \%$ switch. This case is included for continuity but is not central to the main topic of this paper. This last case is illustrated in Fig. 3(d).

Figs. 4-6 show data generated with fault cases described earlier. In each of the figures, data are shown for $360^{\circ}$, or one complete commutation switching sequence of the phases. Since the rotor pole pairs are oriented axially, the motor has $1440{ }^{\circ}$ for 


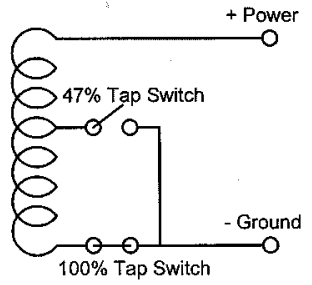

(a)

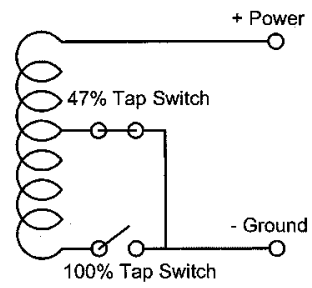

(b)

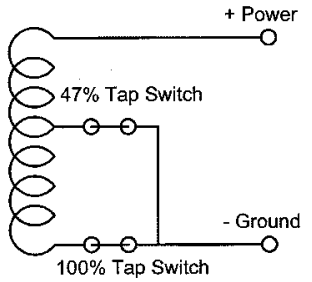

(c)

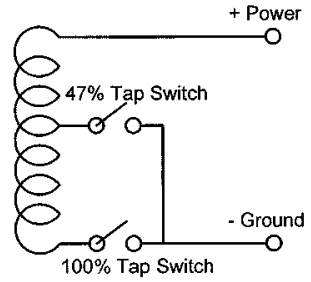

(d)

Fig. 3. Experimental fault simulation phase with tap switches shown: (a) No-fault: $100 \%$ switch closed only. (b) Reduced-coil fault: $47 \%$ switch closed only. (c) Turn-to-turn short fault: both $47 \%$ and $100 \%$ switches closed. (d) Open phase: all switches open.
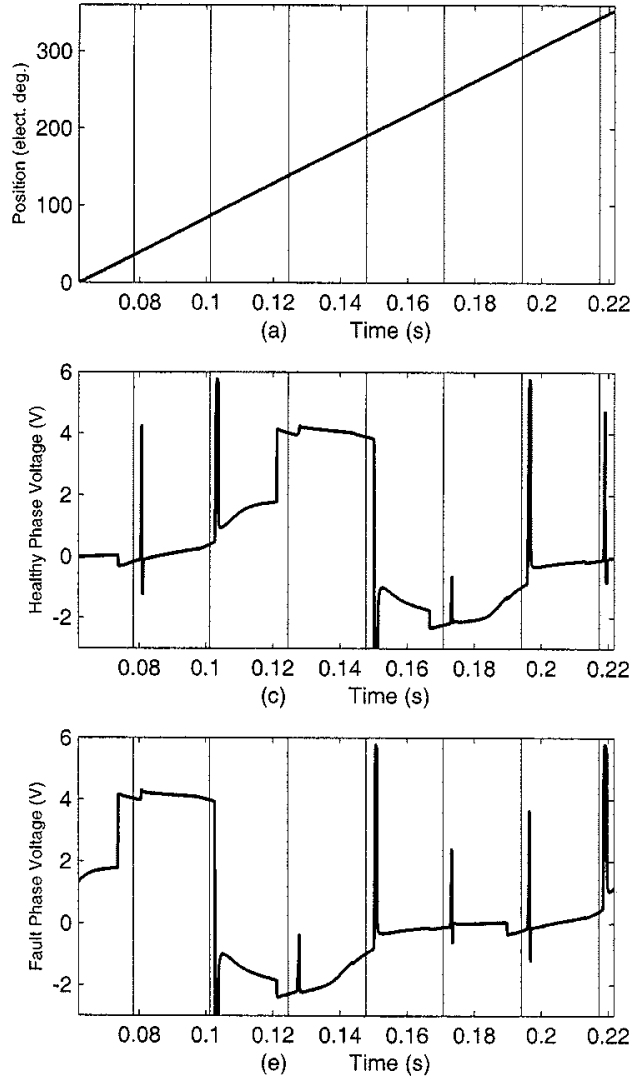

Fig. 4. No fault motor operation data (case 1).

each full revolution of the rotor; hence, each plot represents data taken during a quarter revolution of the rotor. In all cases, time is plotted as the independent variable on the $x$-axis. The vertical lines in each of the plots mark off the commutation sector divisions (i.e., the points in time where one phase is switched off and another is switch on).

In Figs. 4-6, rotor position and velocity are shown in panels (a) and (b), respectively. The velocity plots were obtained by numerically differentiating the position data in each of the three cases.

For each of the cases, the velocities were averaged over the period of time shown in panels Figs. 4(b) and 6(b). These averages were compared as a percent of the nominal average no-fault velocity. These data are summarized in Table I.

Panels (c) and (d) of Figs. 4-6 show voltage and current respectively, measured on a normal healthy stator phase (phase 2). All voltages and currents were measured at the stator coil leads on the motor side of the driver transistor relays.
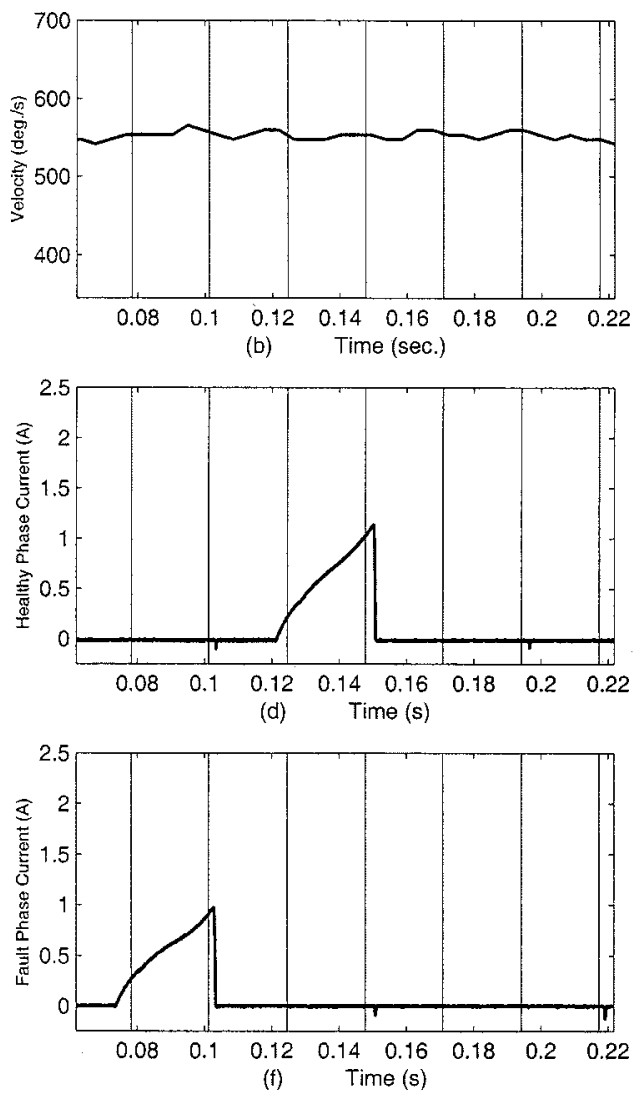

Phase excitation is controlled by the electronic commutation steering circuit in response to rotor position signals. Phase 2 is energized through the commutation steering circuit during the third full commutation sector shown. For panels (c) and (d) of Figs. 4-6, this results in a level peak of approximately $4.2 \mathrm{~V}$ and a current peak starting at $0 \mathrm{~A}$ and rising approximately linearly to roughly $1.1 \mathrm{~A}$. The healthy phase only draws current during its commutation sector. In contrast, a changing voltage, due to PM rotor-induced back emf, is seen in the healthy phase during the entire commutation sequence [see Fig. 4(c) and (e)]. For each of the three test cases, the plots of voltage and current for the healthy phase remain similar.

Voltage and current measurements for the experimental fault simulation phase are plotted in panels (e) and (f) of Figs. 4-6. In the nominal no-fault case, the voltage and current plots for the fault phase are similar to those for the healthy phase, except that they are shifted two phase sectors to the left due to the commutation of the phases. 

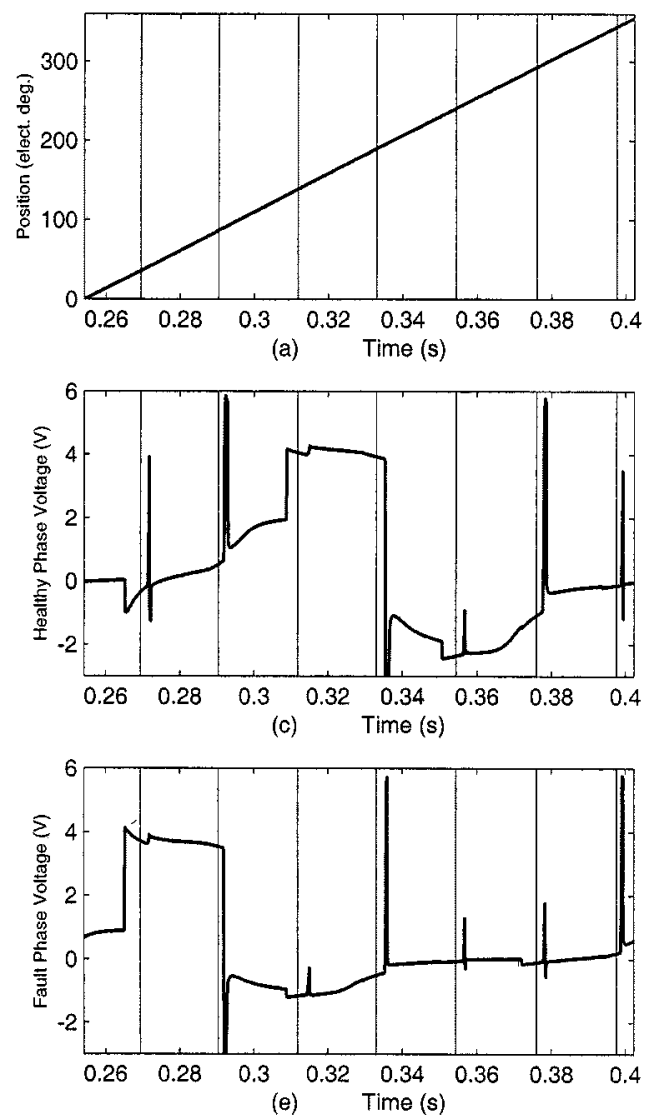

Fig. 5. Motor operation with the reduced-coil fault (case 2).

In each of the experimental conditions, the current and voltage graphs of the healthy phase remain relatively similar. In contrast, cases 2 and 3 show a 302.6 and $303.2 \%$ increase in mean current draw compared to the no-fault case, respectively. These correspond to the reduced-coil fault and the turn-to-turn fault, respectively, and are shown in Figs. 5(f) and 6(f). Both the reduced-coil fault and the turn-to-turn fault show similar current response for the data shown. The current data for each case were plotted on the same axis against rotor position. This is shown in Fig. 7(a). To compare the relative current profiles of the reduced-coil fault and the turn-to-turn fault with respect to the no fault case, difference curves where generated. The nominal no-fault current was subtracted from each of these two fault cases. The resulting curves were plotted on the same axis and are shown in Fig. 7(b).

The voltage data of each case were plotted on the same axis against rotor position. This is shown in panel Fig. 8(a). To compare the relative voltage profiles of the reduced-coil fault and the turn-to-turn fault with respect to the no fault case, difference curves where again generated. The nominal no-fault voltage was subtracted from each of these two fault cases. The resulting curves were plotted on the same axis and are shown in Fig. 8(b).

As noted earlier, the voltage and current profiles of the reduced-coil fault and the turn-to-turn fault are similar. These fault cases can be most easily differentiated from their associated steady-state rotor velocities. The reduced-coil fault produces an average rotor velocity of $599.76^{\circ} / \mathrm{s}$, while the turn-to-turn fault
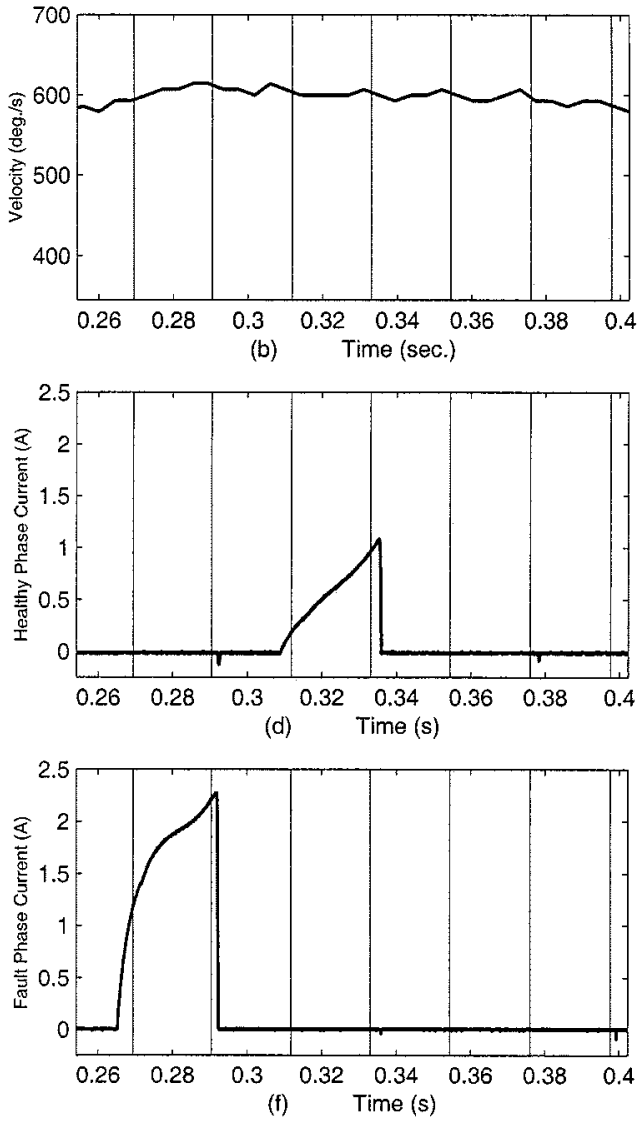

produces an average rotor velocity of only $463.17^{\circ} / \mathrm{s}$. These are shown in Figs. 5(b) and 6(b), respectively. Fig. 9(a) shows velocity graphs with respect to rotor position for the no-fault case, the reduced coil case, and the turn-to-turn case. Fig. 9(b) shows the difference between the no-fault case and the reduced coil and the turn-to-turn cases. These differences in velocity are attributed to damping currents associated with coil shorts and are discussed in the following section.

The current through the $47 \%$ tap switch was also measured in each case. Fig. 10 shows the current measured through the $47 \%$ tap switch for each of the experimental configurations.

\section{Discussion AND ANALYSIS}

\section{A. Overview and Identification of Damping Current}

The most salient difference between the results of the data taken in case 2 (the reduced-coil fault), and in case 3 (the turn-to-turn failure) is seen in the velocity plots [Figs. 5(b) and 6(b)]. The reduced-coil fault results in an average rotor velocity of $599.76 \%$ s. This is $108 \%$ of the no-fault velocity. In comparison, case 3, the turn-to-turn short fault produces an average rotor velocity of $463.17 \%$ s which is only $83 \%$ of the no-fault case. This rotor velocity damping is due to a damping current induced in the shorted portion of the faulted coil by the relative motion of the permanent magnet rotor.

Fig. 11 shows a diagram of the experimental fault simulation phase configured for the turn-to-turn fault. The path seen by current from the power source is indicated by the gray line $i_{1}$. 

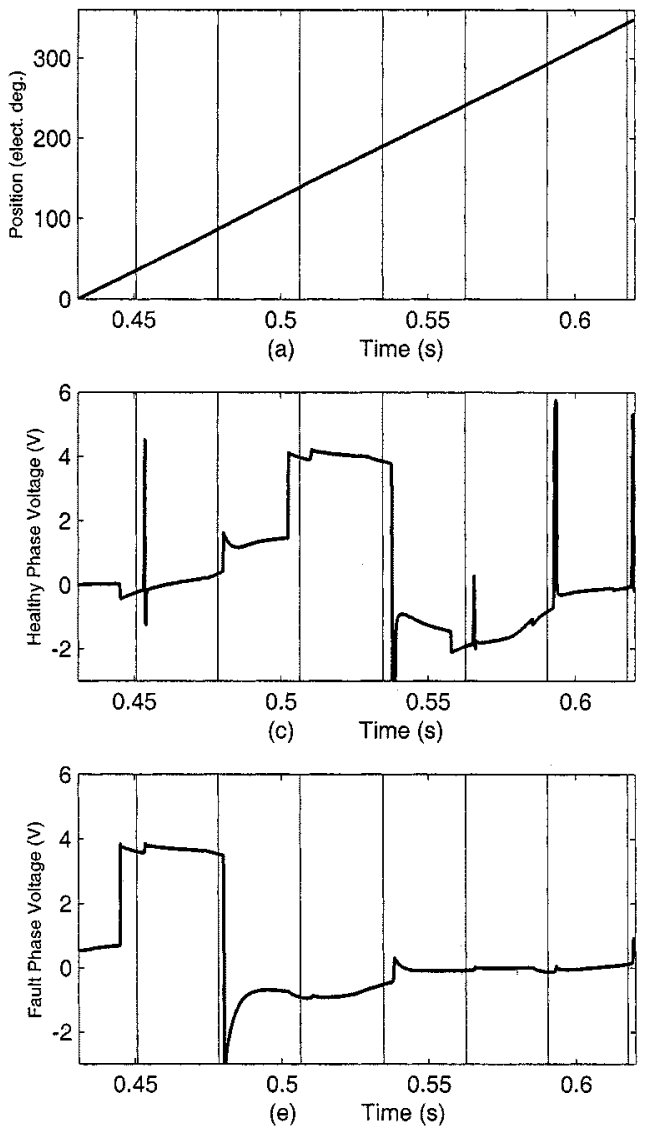

Fig. 6. Motor operation with the turn-to-turn fault (case 3).

TABLE I

Average Velocities and Percentage of Nominal No-Fault Velocity FOR CASES 1 THROUGH 3

\begin{tabular}{l|l|c|l}
\hline & Case 1 & Case 2 & Case 3 \\
\hline Avg. Velocity (deg/s) & 556.035 & 99.76 & 463.17 \\
\hline$\%$ of Nominal & $100 \%$ & $107.8 \%$ & $83.3 \%$ \\
\hline
\end{tabular}

$i_{1}$ only flows when the phase is commutated (i.e., when it is energized by the source). As the rotor moves in relation to the stator coils, an emf is induced. In the turn-to-turn fault, there is a closed circuit that permits current flow. The path seen by the current $i_{2}$ due to the PM rotor induced emf is shown by the dotted line in Fig. 11. $i_{2}$ produces a back mmf that opposes rotor motion at all times during its rotation. The current through the $47 \%$ tap switch, $i_{47 \% \text { tap }}$, can be written in terms of the currents $i_{1}$ and $i_{2}$ as

$$
i_{47 \% \operatorname{tap}}=i_{1}-i_{2} \text {. }
$$

It is clear from (1) that $i_{2}$, the current induced in the faulted portion of the coil, can be obtained by subtracting $i_{47 \% \text { tap }}$ from $i_{1}$. It is evident from the current data shown in Fig. 10 of the previous section that no current flows through the $47 \%$ tap switch in the no-fault or open-phase fault cases. For the reduced-coil fault case and the turn-to-turn fault case, $i_{2}$ was calculated using (1). These results are shown in Fig. 12 and represent current flowing only in the faulted portion of the coil. It is clear that there is no
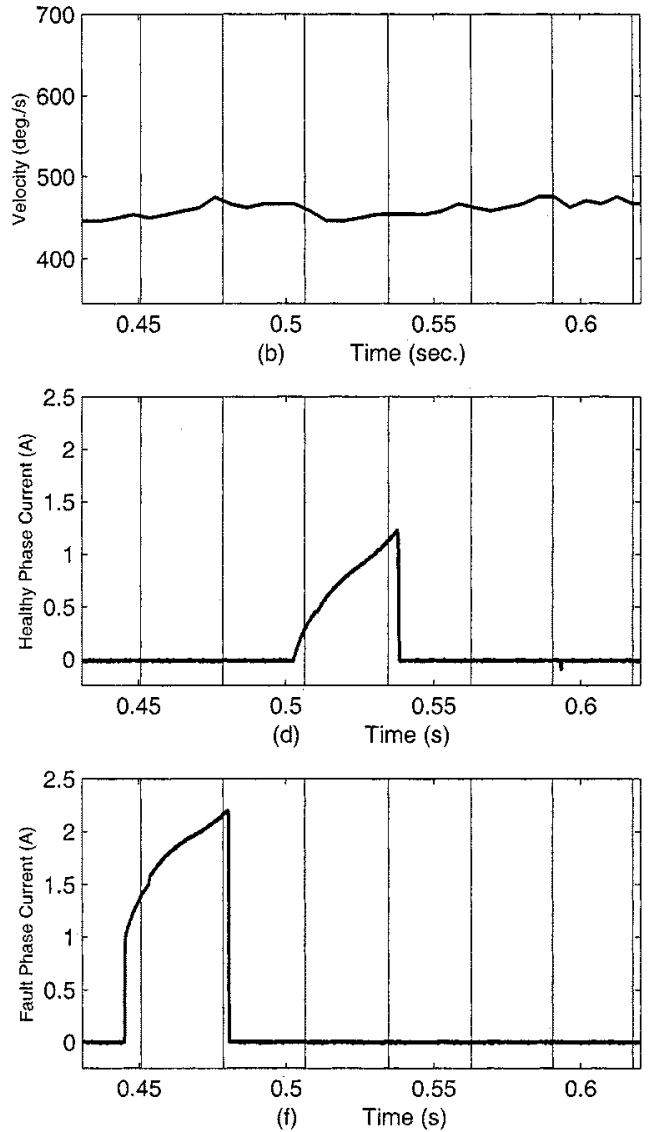

net current induced by the faulted portion of the coil in the reduced coil case. In contrast, the turn-to-turn case clearly shows a current that persisted throughout the rotation of the rotor.

The case 3 turn-to-turn short fault differs significantly from the other cases. It alters the behavior of the faulted phase coil not only when the faulted phase coil is energized by the power source during its commutation phase but also when it is disconnected from the power source during the commutation of the other phases. As in the case of an insulation failure-induced coil short, the turn-to-turn short fault creates a closed circuit loop that remains, even when the phase is not energized by the source. This results in a damping torque as the PM rotor moves in relation to the closed current loop and induces a current flow. The induced current persists during the entire rotation of the rotor.

\section{B. Formulation of a Mathematical Expression for Damping Torque}

To investigate this damping further, we will develop an expression for the fault-induced damping torque. The motor used in this work can be described by standard VR motor modeling dynamic equations such as those described in [3]-[5]. Here, we will make use of the standard equations for torque and inductance given below in (2) and (3).

The net electrical torque applied to the rotor by a given stator coil can be written as

$$
T_{m}=\frac{1}{2}\left(i_{m}\right)^{2} \frac{\partial L_{m}(\theta)}{\partial \theta}
$$




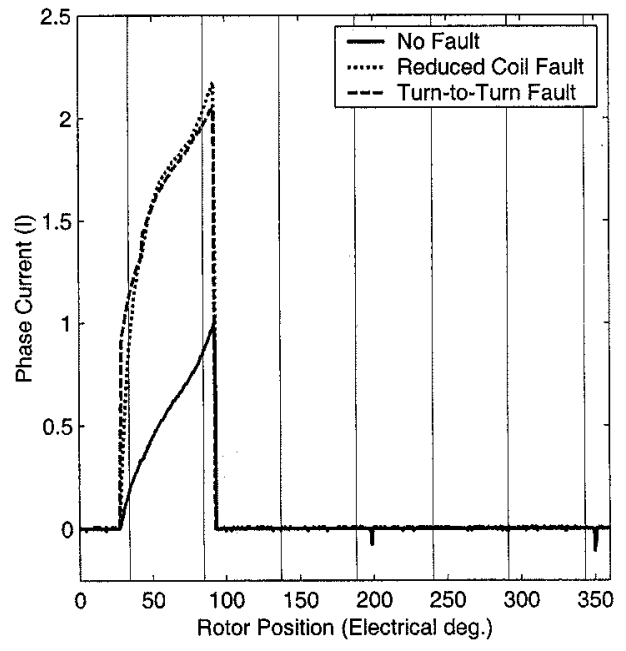

(a)

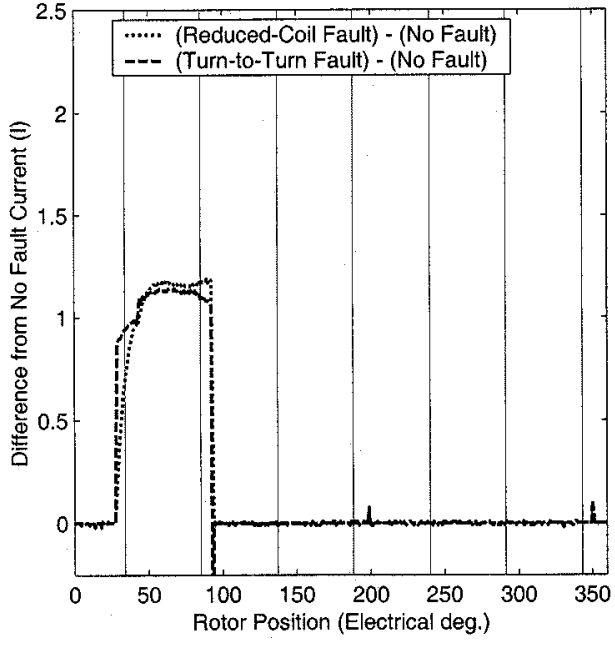

(b)

Fig. 7. (a) Phase current draw for the no-fault case, the reduced-coil fault, and the turn-to-turn fault. (b) Differences between each of the two fault cases and the no-fault case plotted together.

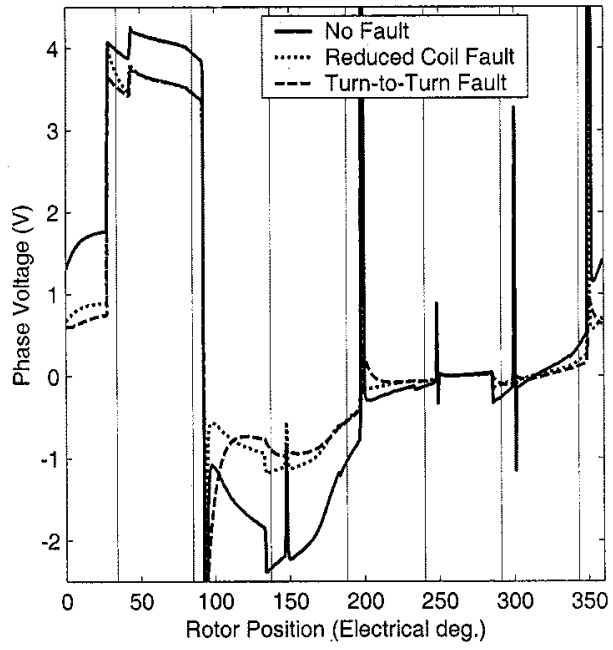

(a)

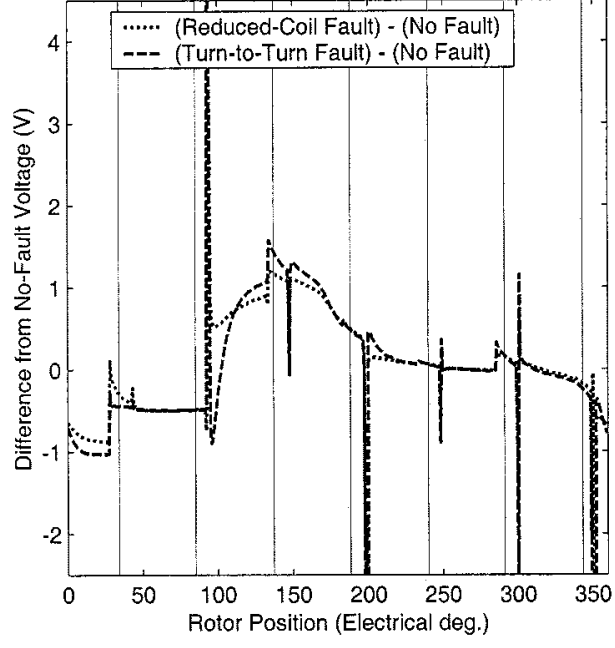

(b)

Fig. 8. (a) Phase voltage for the no-fault case, the reduced-coil fault and the turn-to-turn fault. (b) Differences between each of the two fault cases and the no-fault case are plotted together.

where $i_{m}, L_{m}$, and $\theta$ are the current in the $m$ th coil, the inductance of the $m$ th coil, and the angular position of the rotor, respectively. Inductance of the $m$ th coil can be given by

$$
L_{m}(\theta)=\frac{\phi_{m}}{i_{m}}
$$

where $\phi_{m}$ is the flux linkage in the $m$ th coil. For purposes of analysis, it will be convenient to express $L_{m}(\theta)$ in the following form:

$$
L_{m}(\theta)=N k_{L} l_{m}(\theta)
$$

where $N, k_{L}$, and $l(\theta)$ are the number of turns per coil, a constant representing the static elements of the flux path (i.e., the permeability of the core and the PMs), and a unit function representing the variable part of the flux path, respectively.
We will use (2) to describe the interaction between the rotor and the faulted portion of the coil:

$$
T_{\text {damp }}=\frac{1}{2}\left(i_{\text {damp }}\right)^{2} \frac{\partial L_{\text {fault }}}{\partial(\theta)}
$$

where $T_{\text {damp }}, i_{\text {damp }}$, and $L_{\text {fault }}$ are the damping torque, the current induced in the faulted portion of the coil, and the inductance of the faulted portion of the coil, respectively. For clarification $i_{\text {damp }}$, is shown as $i_{2}$ in Fig. 11. Since spatial relationships and material permeabilities are not altered in the fault case, the difference between the inductance associated with an unfaulted coil, and the inductance of the faulted portion of the experimental fault simulation coil is reflected in the number of winding turns. With this in mind, and using(4), we can express the partial of $L_{\text {fault }}(\theta)$ with respect to $\theta$, as

$$
\frac{\partial L_{\text {fault }}(\theta)}{\partial \theta}=N_{\text {fault }} k_{\text {Lfault }} \frac{\partial l_{m}(\theta)}{\partial \theta} .
$$




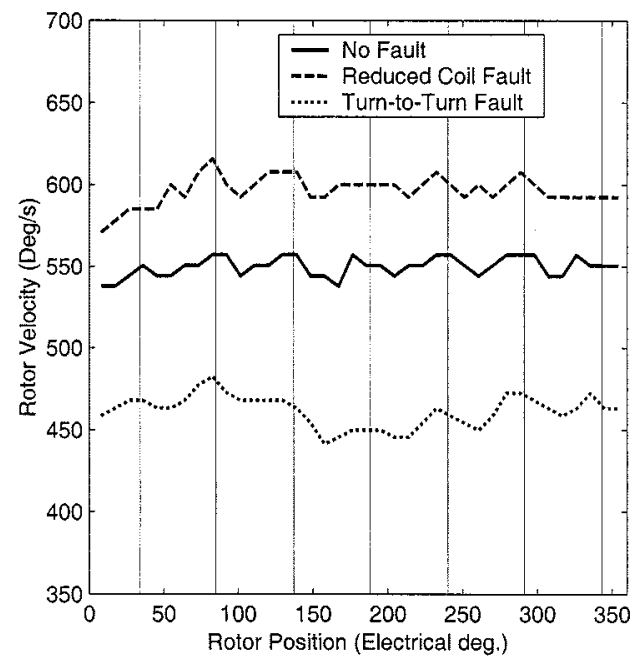

(a)

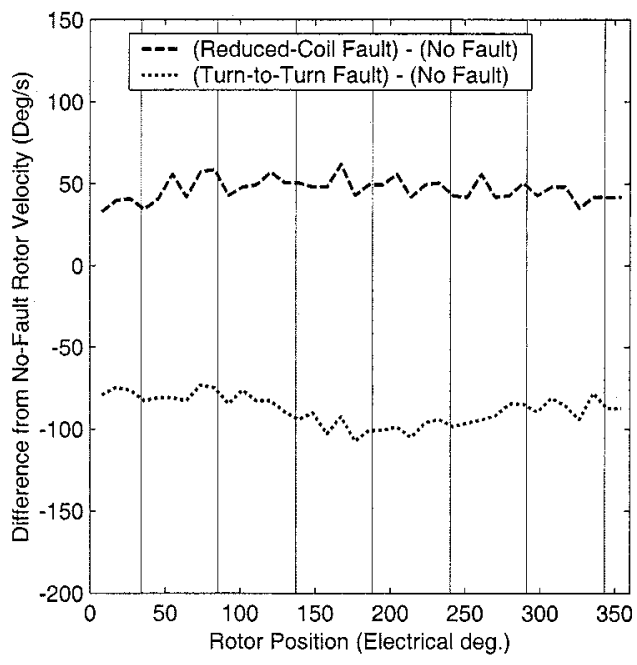

(b)

Fig. 9. (a) Velocity for the no-fault case, the reduced-coil fault and the turn-to-turn fault. (b) Differences between each of the two fault cases and the no-fault case plotted together.
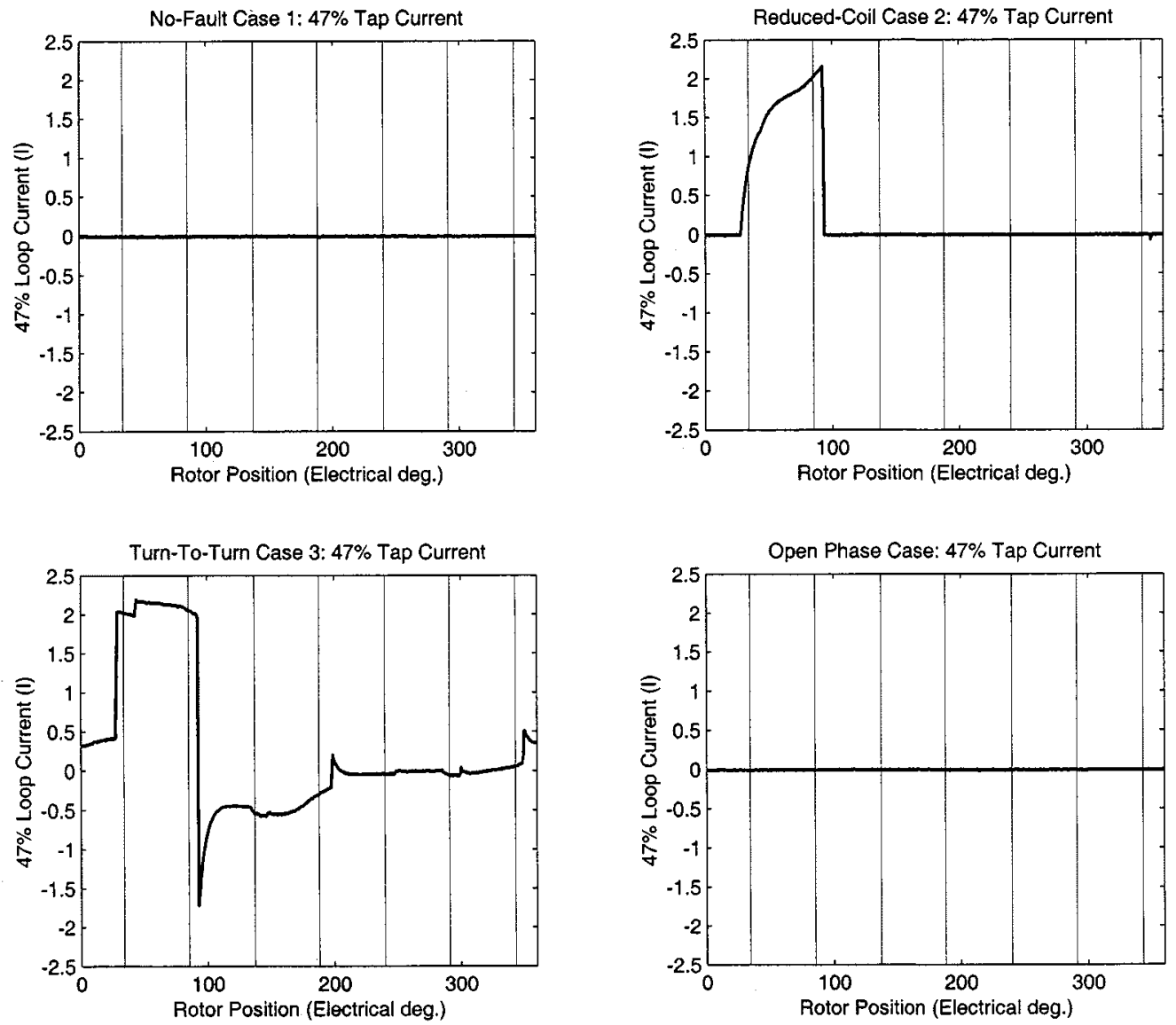

Fig. 10. Current draw through the $47 \%$ tap switch in each of the four experimental configurations. Data are shown for 360 electrical degrees.

In this case, $l_{m}$, which is the unit function representing the variable part of the flux path, is the same as for the unfaulted coil. In addition, $k_{L \text { fault }}$ is also unchanged from its no-fault value. Therefore, $k_{L \text { fault }}$ can be replaced by $k_{L}$ in (6). Since we are considering only one coil, we will drop the $m$ subscripts. Introducing $N=N_{\text {noFault }}$ into (6) and substituting this into (5), we can now express the turn-to-turn fault damping torque in terms of $i_{\text {damp }}$ (the current in the faulted portion of the coil) and a faulted turns ratio

$$
\begin{aligned}
T_{\text {damp }} & =\frac{1}{2}\left(i_{\text {damp }}\right)^{2}\left(\frac{N_{\text {fault }}}{N_{\text {noFault }}}\right) N_{\text {noFault }} k_{L} \frac{\partial l(\theta)}{\partial(\theta)} \\
& =\frac{1}{2}\left(i_{\text {damp }}\right)^{2}\left(\frac{N_{\text {fault }}}{N_{\text {noFault }}}\right) \frac{\partial L(\theta)}{\partial(\theta)} .
\end{aligned}
$$




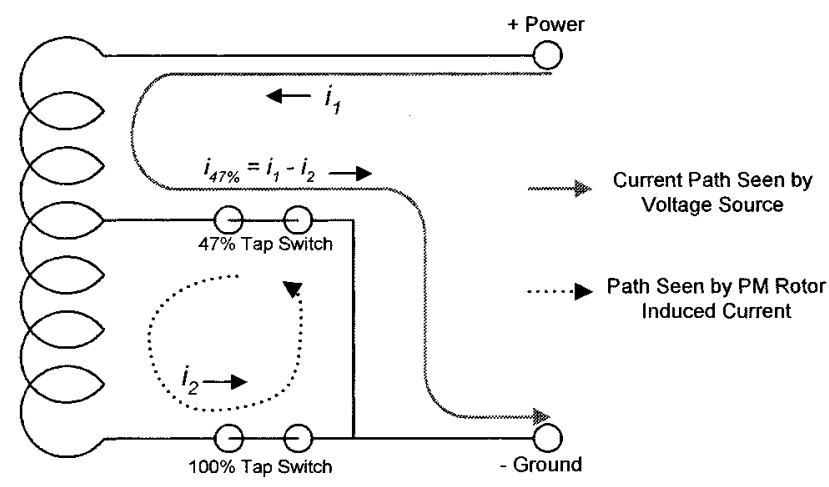

Fig. 11. Power-source and back emf-induced current paths in the turn-to-turn faulted coil.
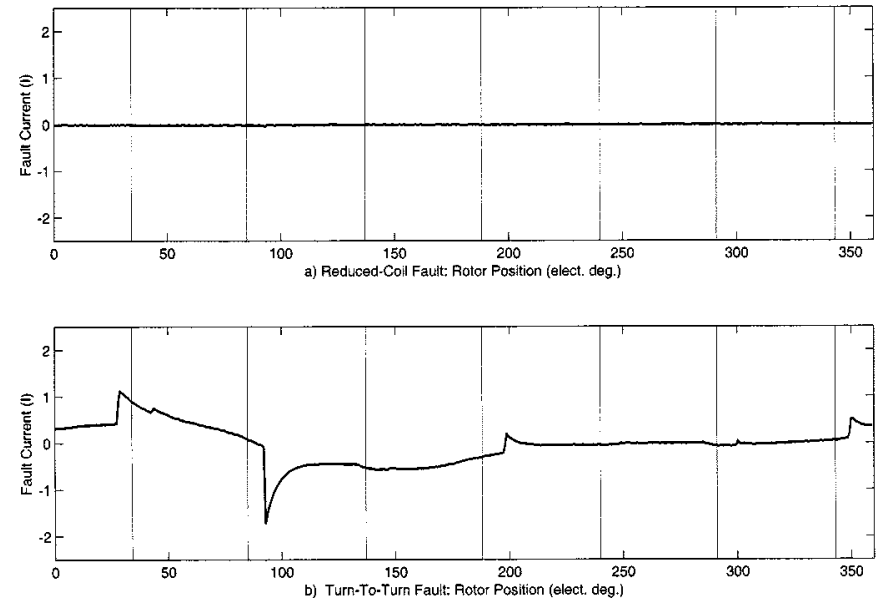

Fig. 12. Net current flow in the faulted portion of the experimental fault simulation coil in (a) the reduced-coil fault case, and (b) the turn-to-turn fault case.

This damping torque always opposes the motion of the rotor, since the origin of the current is the rotor-induced-back emf.

We will address overall average steady-state torque from the point of view of average torque developed by the motor when one of the healthy phases is energized. In this case, the total average fault condition torque $T_{\text {fault }}$ is given by

$$
T_{\text {fault }}=T_{\text {healthy }}-T_{\text {damp }}
$$

where $T_{\text {healthy }}$ [i.e., $T_{m}$ from (2)] is the torque generated by a nonfaulted phase, and $T_{\text {damp }}$ is given in (7). Since the phases in this motor are electrically and magnetically isolated, torque production in the healthy phases is not affected by the fault, although the overall motor torque is reduced due to the damping torque. Substituting (2) and (7) into (8), we get

$$
\begin{aligned}
T_{\text {fault }} & =T_{\text {healthy }}-T_{\text {damp }} \\
& =\frac{1}{2}\left(\left(i_{\text {healthy }}\right)^{2}-\left(i_{\text {damp }}\right)^{2}\left(\frac{N_{\text {fault }}}{N_{\text {noFault }}}\right)\right) \frac{\partial L(\theta)}{\partial(\theta)} .
\end{aligned}
$$

Since only one phase is energized at a time with the brushless driver, (9) can be used for average net motor torque. Then, factoring the $\left(i_{\text {healthy }}\right)^{2}$ out of (9) and substituting in for $T_{\text {healthy }}$ from (2), we can express the ratio of the no fault torque to the turn-to-turn fault torque as

$$
\frac{T_{\text {fault }}}{T_{\text {healthy }}}=\left(1-\frac{\left(i_{\text {damp }}\right)^{2}}{\left(i_{\text {healthy }}\right)^{2}}\left(\frac{N_{\text {fault }}}{N_{\text {noFault }}}\right)\right) .
$$

Equation (10) can be used to predict the approximate average percent of torque reduction due to the measured damping current, $i_{\text {damp }}$ (shown as $i_{2}$ in Fig. 11). This is expressed in terms of measured currents and the ratio of the number of turns shorted to the number of turns in a healthy phase. This information can then be compared to known torque profiles for a given motor, and can be used as an indication of the degree of turn shorting in a faulty coil.

\section{CONCLUSIONS AND FutURE RESEARCH}

In this work, a prototype axial flux VR PM motor was discussed. This motor was designed to be a low-power version of machines similar to a class of experimental electric vehicle propulsion motors. Motors of this type possess a high degree of inherent fault tolerance and may continue to operate with relatively little degradation in torque production in the presence of relatively severe faults.

The motor was used to study stator winding faults. One of the motor's phases was modified so that it could be used to experimentally simulate stator winding faults.

Data were presented for several types of stator winding faults. In particular, turn-to-turn faults were examined. It was found that a major turn-to-turn fault is associated with a reduction in rotor velocity when the motor is driven with a brushless driver with closed-loop rotor position feedback and open-loop voltage-speed control.

Fault characterization results, such as those presented in this paper, are a necessary first step in the process of fault detection and diagnosis in a particular motor topology. Fault detection and diagnosis in induction motors have received considerable attention in the literature (see [9] for example). Fault detection in permanent magnet and brushless motors have received much less attention (see [10] for a recent example).

The voltage and current traces are similar in the cases of fault 2 and 3 [see panels (e) and (f) in Figs. 5 and 6]. The current induced in the shorted coils is not detected by the external current sensor, since it flows entirely in the interior of the coil. This current can be an order of a magnitude higher than rated current [1],[6], and can lead to a cascade failure in the coil as heat generated in the shorted turns deteriorates the insulation of neighboring turns and introduces more shorts. A safety hazard could result if a fault goes undetected and leads to the sudden catastrophic failure of the motor. Hence, it is desirable to have metric to characterize this fault. The results presented in this work suggest that a change in rotor velocity under conditions of constant load may be useful for detecting the turn-to-turn fault and differentiating it from other winding faults.

In the case of open-loop voltage-speed controllers, such as those used to drive the motor used in these experiments, a change in rotor speed can be detected as a result of the damping discussed in this paper. In cases of constant velocity drives used on fault-tolerant SR motors, an associated rise in current 
in the healthy phases can be detected as the driver compensates for the additional damping load caused by the faulted phase [2], [7], [8].

These results may be most applicable to open-loop speed control systems, such as those used in some electric vehicles and machines designed to operate directly by humans. See [11] for an example of application of a PM axial flux motor in an electric vehicle. These systems are technically closed-loop systems where the operator (a human) is acting as a complex dynamic proportional controller. In such cases, under a known load, a particular input voltage will be associated with a particular rotor velocity in the no-fault condition. In some systems, it may be possible to detect a deviation from this expected velocity and report it independently of a dynamic in-the-loop controller such as a human.

\section{REFERENCES}

[1] J. A. Haylock, B. C. Mecrow, A. G. Jack, and D. J. Atkinson, "Operation of fault tolerant machines with winding failures," IEEE Trans. Energy Conversion, vol. 14, pp. 1490-1495, 1999.

[2] A. G. Jack, B. C. Mecrow, and J. A. Haylock, "A comparative study of permanent magnets and switched reluctance motors for high performance fault tolerant applications," in Conf. Rec. IAS IEEE Ind. Applicat. Conf., vol. 1, 1995, pp. 734-740.

[3] C. C. Chan, J. Z. Jiang, H. G. Chen, X. Y. Wang, and K. T. Chau, "A novel polyphase multipole square-wave permanent magnet motor drive for electric vehicles," IEEE Trans. Ind. Applicat., vol. 30, pp. 1258-1266, Sept./Oct. 1994.

[4] J. F. Eastham, M. J. Balchin, T. Betzer, H. C. Lai, and S. Gair, "Disc motor with reduced unsprung mass for direct EV wheel drive," in Proc. IEEE Int. Symp. Ind. Electron., vol. 2, July 10-14, 1995, pp. 569-573.

[5] S. A. Nasar and I. Boldea, Electric Machines Steady-State Operation. New York: Hemisphere, 1990.

[6] F. Caricchi, F. Crescimbini, and A. Di Napoli, "Prototype of innovative wheel drive with water-cooled axial-flux PM motor for electric vehicle applications," in Proc. IEEE APEC Conf. , vol. 2, 1996, pp. 764-770.

[7] C. M. Stephens, "Fault detection and management systems for fault tolerant switched reluctance motor drives," IEEE Trans. Ind. Applicat., vol. 27, pp. 1098-1102, Nov./Dec. 1991.

[8] S. Nandi and H. A. Toliyat, "Fault diagnosis of electrical machines-A review," in Proc. IEEE Int. Elect. Machines Drives Conf., 1999, pp. 219-221.

[9] W. T. Thomson and M. Fenger, "Current signature analysis to detect induction motor faults," IEEE Ind. Applicat. Mag., vol. 7, pp. 26-34, Sept. 2001

[10] O. Moseler and R. Isermann, "Application of model-based fault detection to a brushless DC motor," IEEE Trans. Ind. Electron., vol. 47, pp. 1015-1020, Oct. 2000.

[11] L. Solero, O. Honorati, F. Caricchi, and F. Crescimbini, "Nonconventional three-wheel electric vehicle for urban mobility," IEEE Trans. Veh. Technol., vol. 50, pp. 1085-1091, July 2001.

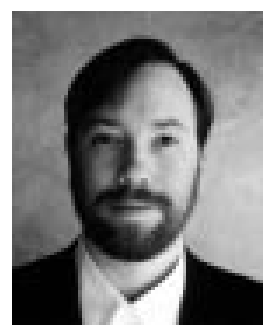

Andrew L. Nelson was born in Laramie, WY, in 1967. He received the B.Sc. degree from Evergreen State College, Olympia, WA, in 1990 and the M.Sc. degree in electrical engineering from North Carolina State University (NCSU), Raleigh, in 2000. Currently, he is pursuing the Ph.D. degree in electrical engineering at the Center for Robotics and Intelligent Machines (CRIM), Department of Computer and Electrical Engineering, NCSU.

Before continuing his post baccalaureate education, he worked as a Laboratory Technician with the Department of Cell and Molecular Biology, University of North Carolina, Chapel Hill, and co-authored several research papers in that field.

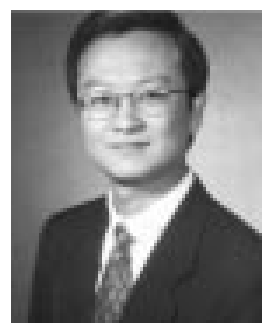

Mo-Yuen Chow (SM'93) received the B.Sc. degree in electrical and computer engineering from the University of Wisconsin, Madison, in 1982 and the M.Sc. and Ph.D. degrees in engineering from Cornell University, Ithaca, NY, in 1987.

Upon completion of the Ph.D. degree, he joined the Department of Electrical and Computer Engineering, North Carolina State University, Raleigh, as an Assistant Professor. He became an Associate Professor in 1993 and has been a Professor since 1999. He has also worked as a consultant for Duke Power Co., OTIS Elevator Co., Taiwan Power Co., J.W. Harley Co., and as a faculty intern at Duke Power Co. His core technology is diagnosis and control, artificial neural networks, and fuzzy logic. Since 1987, he has been applying his core technology to areas including motors, process control, power systems, and communication/networking systems. He has served as a Principal Investigator in several projects supported by the National Science Foundation, Center for Advanced Computing and Communication, Nortel Company, the Electric Power Research Institute, Duke Power Co., ABB Co., the Electric Power Research Center, and the Army Construction Engineering Research Laboratory. He established the Advanced Diagnosis and Control (ADAC) Laboratory at North Carolina State University. He has published one book, several book chapters, and more than 80 journal and conference articles related to his research work.

Dr. Chow served as a Guest Editor for the IEEE TRANSACTIONS ON INDUSTRIAL ELECTRONICS Special Issue on Application of Intelligent Systems to Industrial Electronics in 1993 and for the Special Issue on Motor Fault Detection and Diagnosis in 2000. He is currently the IEEE Industrial Electronics Society Vice President for Member Activities, an Associate Editor for the IEEE TRANSACTIONS ON INDUSTRIAL EleCtronics, Technical Co-Chair of International Joint Conference on Neural Networks 2001, an Ad Com member of the IEEE Industrial Electronics Society, an Ad Com member of the IEEE Neural Network Council, Chairman of IEEE Neural Network Council Regional Interest Group Committee, past Editor-in-Chief of IEEE Industrial Electronics Society Newsletter, and past President of the Triangle Area Neural Network Society. In addition, he is listed in Who's Who of Asian Americans. 